\title{
FOTO IKLAN LAYANAN MASYARAKAT TENTANG KESEHATAN DALAM KARYA FOTOGRAFI KREATIF
}

\author{
Adia Damar Syamsuri, Ida Susanti \\ Program Studi Fotografi, Jurusan Penerbitan, \\ Politeknik Negeri Media Kreatif Jakarta
}

\begin{abstract}
This research aims at creating public service advertisement photos about public health in a creative photographic work. The public health themes used are six aspects e.i. smoking, obesity, narcotics, liquor, epilepsy, HIV and AIDS. The contents are about convincing people to live healthier and leave the negative things that are detrimental to health. In addition, the researcher wants to remove negative paradigm that is always present in the minds of the public about the disease called a nerve disorder, epilepsy or "Ayan". Making of photos are done with tools and materials in accordance with the concept of assisted photo shoots with the help of Digital Imaging. The researcher uses the technique of shooting High Key. He uses a mini studio with two lights flash strobe for shooting the object man and light tent mini studio for shooting objects in the form of inanimate objects with small to moderate size.
\end{abstract}

Keywords: Photography, advertisement, public services, creative work

\section{PENDAHULUAN}

Kurangnya perhatian masyarakat pada kesehatan, terutama oleh para generasi muda membuat resah betapa bahaya pola hidup mereka. Mereka butuh orang lain untuk mengingatkan sebelum adanya kesadaran yang tumbuh di dalam diri sendiri. Hal itu yang membuat penulis mencoba mengangkat Foto Iklan Layanan Masyarakat tentang Kesehatan dalam Karya Fotografi Kreatif.

Beberapa isu yang penulis angkat di antaranya persoalan Rokok, Obesitas, Narkotika, HIV dan AIDS, Minuman Keras, serta Epilepsi yang sangat dekat dengan kehidupan penulis sehingga dapat merealisasikan konsep-konsep tema tersebut dengan maksimal. Banyak orang menganggap remeh hal-hal tersebut serta acuh tak acuh dalam bersikap akan krisis kesehatan ini yang menjadikan hal menakutkan jika tidak ada kesadaran dan aksi dari orang-orang yang masih peduli tentang kesehatan.

Pembatasan masalah di sini adalah penggunaan teknik foto studio indoor menggunakan sebuah mini light tent studio yang penulis miliki, di tambah dengan peralatan fotografi yang cukup mendukung untuk membuat 20 buah konsep Foto Iklan 
Layanan Masyarakat Tentang Kesehatan Dalam Karya Fotografi Kreatif. Fokus masalah dalam karya tugas akhir ini adalah bagaimana cara memotret foto iklan tersebut menggunakan alat dan bahan yang seadanya namun dapat menyampaikan maksud dan pesan dalam foto dengan baik dan mudah dipahami.

Fotografi Still life dalam konteks fungsional berupa pemotretan benda untuk tujuan pembuatan katalog, brosur, company profile, flyer dan iklan. Dalam hal ini, still life berfungsi sebagai iklan atau komunikasi visual dalam konteks komersial.Semua foto yang dibuat harus komunikatif; seberapa bagus desain barangnya, bagaimana fungsi barangnya dan diperuntukkan untuk kalangan siapa barang yang ada dalam foto tersebut.Fotografi Still life dalam konteks ekspresif, foto still life dibuat sesuai selera, konsep dan emosi fotografer yang membuat foto still life tersebut.Seorang fotografer dapat mengekspresikan diri ke dalam fotonya.

Dalam praktik pembuatan foto yang penulis lakukan, semua yang Anang tulis sangat relevan dan dapat dibuktikan.Pada pembuatan karya foto penulis mencoba menggabungkan kedua konteks fotografi still life yang dianut oleh Anang dan diterapkan oleh penulis. Dimana semua foto yang penulis buat lebih mengacu kepada karakter sang fotografer yang dituangkan dalam karya fotonya namun juga tetap memiliki nilai fungsional sebagai penyampai pesan kepada masyarakat dikarenakan tuntutan untuk menyesuaikan dengan konsep dan judul yang diangkat oleh penulis. Fotografi Studio adalah fotografi yang dilakukan di dalam ruangan menggunakan lampu flash berupa strobe atau pun speedlite yang diberi karakter sesuai dengan keinginan fotografer yang dapat direkayasa sesuai dengan keinginan dan kebutuhan fotografer untuk menghasilkan foto yang maksimal. Dasar alasan penulis melakukan semua foto di studio secara indoor menggunakan peralatan mini studio yang cukup untuk menampung semua objek foto terutama untuk Karya Tugas Akhir ini adalah karena semua konsep foto ini memerlukan setting yang cukup presisi membuat tidak mungkin pemotretan dilakukan di outdoor yang hanya mengandalkan cahaya matahari yang tidak dapat diatur besaran kekuatan cahaya serta variasi angle yang diinginkan.

Dalam proses pemotretan, penulis menggunakan studio mini bernama mini light tent studio, benda tersebut beraneka ragam ukurannya dimulai dari ukuran terkecil 40x40x40 centimeter hingga yang terbesar berukuran $150 \times 150 \times 150$ centimeter terbuat dari kain lentur yang kuat diperkuat oleh rangka kawat fleksibel yang dapat ditekuk sehingga memnugkinkan benda ini dapat dilipat hingga berukuran kecil dengan ukuran hanya 20-60 centimeter dengan bentuk pipih dan 
sangat ringan, sehingga tidak menghabiskan tempat untuk penyimpanannya. Penulis menggunakan mini light tent studio berukuran 110x110x110 centimeter dengan pertimbangan tempat memotret juga kepraktisan bongkar pasang dalam ruangan.

Dalam buku Semiotika Komunikasi (Edisi 2) karya Idiwan Seto Wahyu Wibowo (2013:7)dijelaskan bahwa Semiotik berasal dari kata Yunani Semeion yang bearti Tanda. Tanda itu sendiri didefinisikan sebagai sesuatu - yang atas dasar konvensi sosial yang terbangun sebelumnya - dapat dianggap mewakili sesuatu yang lain. Tanda pada awalnya dimaknai sebagai sesuatu hal yang menunjuk pada adanya hal yang lain. Contohnya adalah adanya asap yang menandakan adanya api, sirene mobil yang keras meraung-raung menandakan adanya kebakaran di sudut kota.Lebih lanjut, Adanya Janur kuning menandakan ada hajatan perkawinan, tapi bila terpasang bendera kuning maka itu pertanda kematian.

\section{METODE PENELITIAN}

Pada awal pengumpulan ide dan referensi karya penulis juga mengobservasi beberapa karya foto iklan layanan masyarakat tentang kesehatan yang sudah ada. Agar tidak terciptanya dua karya yang sama dari dua fotografer yang berbeda karena dapat menjadi permasalahan atas tuduhan plagiat. Observasi dengan metode mencari buku referensi dari berbagai macam penulis serta penerbit lokal dan internasional yang terdapat di perpustakaan Kampus Polimedia Jakarta serta beberapa buku yang penulis sengaja beli untuk keperluan pembelajaran dan penerapan materi yang terkandung di dalam buku tersebut sedangkan metode dengan browsing Internet dilakukan untuk pencarian bahan landasan teori dan referensi tokoh serta acuan karya berupa foto yang ada di website/blog tokoh referensi ataupun penggiat penulis bidang fotografi.

Praktik pemotretan objek benda mati, sesuai dengan namanya Still Life. Pemotretan dilakukan di rumah dengan peralatan dan bahan seadanya berupa studio mini buatan sendiri yang mengacu pada referensi di internet dan buku karya Yuliandi Kusuma. Teknik fotografikali ini menggunakan teknik foto High Key, dimana background foto berwarna putih polos yang dipadukan kedalam konsep foto iklan kreatif dimana membahas isu kesehatan masyarakat seperti yang sudah dituliskan di halaman 1 (satu) pada bagian Segi Kesehatan.

Teknik High Key sendiri merupakan pemotretan yang menitik beratkan pada arahighlight yang begitu dominan sehingga background foto cenderung putih, namun tanpa menghilangkan detil dari objek foto. Penggunaan teknik High Keyjuga memperbesar perhatian kepada subyek, namun kesan yang ditimbulkannya berlawanan dengan kesan yang 
timbul oleh dominasi shadow pada Low Key. Besarnya porsi highlight pada foto High Keymenimbulkan kesan cerah, terbuka, gembira, dan sejenisnya. Sementara beberapa sisanya menggunakan objek foto manusia. Sebagian besar dari foto iklan ini juga menggunakan teknik Foto Still Life

$$
\text { Pemotretan still life }
$$
menggunakan teknik High Keykebanyakan menggunakan strobis dan fotografi studio. Beberapa foto diambil menggunakan lensa fix macro $100 \mathrm{~mm}$ sehingga ketajaman dan kedetilan gambar yang dihasilkan jauh lebih bagus ketimbang lensa fix biasa.

Selain itu, karena membutuhkan detil yang tinggi, maka diperlukan ruang tajam yang luas sehingga semua sisi objek dapat terlihat tajam. Kosekuensinya, dengan penggunaan bukaan diafragma sempit membuat cahaya yang tertangkap sangat sedikit.Ditambah kecepatan rana yang harus diatur diatas 1/30 agar minim goyangan tangan maupun getaran-getaran.

Dalam penyusunannya, diperlukan pula referensi karya dari buku-buku yang ada di perpustakaan kampus dan juga dari buku-buku fotografi milik pribadi yang menyangkut dengan materi Foto Tugas Akhir penulis. Ditambah dengan beberapa referensi dari internet sekedar untuk melengkapi beberapa kekurangan yang tidak terdapat pada versi cetak.Termasuk beberapa foto-foto karya
referensi.Buku-buku yang penulis beli diantaranya adalah:

a. Semiotika Komunikasi (Edisi 2) karya Indiwan Seto Wahyu Wibowo, terbitan Mitra Wacana Media tahun 2013.

Dalam buku ini, Indiwan Seto Wahyu Wibowo menjabarkan definisi dari semiotika berdasarkan penjabarannya sendiri, yang diikuti oleh definisi dari beberapa tokoh pakar Semiotika diantaranya Charles Sander Pierce, Ferdinand De Saussure, Roland Barthes serta Umberto Eco.Selain itu, Indiwan membahas studi kasus semiotika yang terdapat di Indonesia diantaranya Pembunuhan Karakter Presiden Gus Dur di Media Massa, Presentasi Maskulinitas dalam tokoh Ayah Pada Iklan Cetak Spagethi La Fonte di Majalah Femina, Konstruksi Kematian Soeharto, Sebuah Analisis Semiotika, serta Sikap SBY dalam Konflik Perbatasan Indonesia-Malaysia (Analisis Makna Pada Karikatur The Jakarta Post Versi Konflik dengan Malaysia) .

b. Buku Saku Fotografi Still Life karya Paulus Edison \& Laely Indah Lestari, terbitan PT Elex Media Komputindo tahun 2012.

Dalam buku ini, kedua penulis mencoba menjabarkan definisi still life menurut pandangan mereka, juga membahas tentang alat-alat yang harus disiapkan sebelum pemotretan termasuk penggunaan beberapa jenis 
kamera dan lensa yang direkomendasikan untuk pemotretan still life.Diikuti dengan tips dan trik memotret still life dengan penjelasan yang mudah dipahami lengkap dengan sketsa pemotretan tiga dimensi yang sangat membantu pembaca. Pada bagian akhir, kedua penulis juga menjelaskan tentang cara mengolah foto still life hingga tips serta tata cara bagaimana cara memulai bisnis menjadi seorang fotografer still life atau produk komersial.

c. Tutorial Step By Step Full ColorFoto Produk Murah \& Wah! Panduan Membuat Foto Produk dengan Peralatan Sederhana karya Yuliandi Kusuma, terbitan PT Grasindo tahun 2010.

Dalam buku ini Yuliandi memberikan tips dan trik untuk melakukan fotografi produk dengan biaya murah meriah dan dapat menggunakan bang-barang disekitar. Mulai dari tips dan cara pembuatan studio mini menggunakan kardus dan kertas kalkir, hingga penggunaan lampu belajar yang diberi stereofoam sebagai diffusercahaya lampu belajar yang bersifat continuous.Selanjutnya Yuliandi menjelaskan cara memotret produk dengan hasil background putih bersih serta menjabarkan proses editing foto pada tahapan selanjutnya setelah sesi foto selesai. d. Strobist - Trik Lighting Kreatif karya Yuliandi Kusuma, terbitan PT Grasindo tahun 2011.

Dalam buku ini Yuliandi lebih menekankan pada teknik lightingstrobist lengkap dengan definisinya. Yuliandi menjelaskan secara lengkap tahapan pemotretan ditambah tips dan trik yang sangat membantu demi mendapatkan hasil foto yang maksimal.

e. Olah Digital Untuk Fotografer karya Yuliandi Kusuma, terbitan PT Grasindo tahun 2011.

Dalam buku ini Yuliandi menjelaskan step by stepcaraediting foto dimulai dari pengenalan software dari layout hingga pengenalan berbagai tombol beserta fungsi yang dapat digunakan. Tidak lupa Yuliandi memasukan komparasi foto sebelum dan sesudah di edit.Beberapa topik yang dibahas Yuliandi pada buku ini adalah mengoreksi foto, menampilkan efek \& filter, membuang objek mengganggu dan retouch menggunakan Photoshop CS5.

\section{HASIL DAN PEMBAHASAN}

Foto still life dengan mengangkat tema Iklan Layanan Masyarakat Tentang Kesehatan menggunakan semiotika dalam beberapa hasil karya yang dibuat. Dengan tujuan menggantikan unsur manusia dalam bentuk sebuah benda mati pada beberapa frame foto yang memungkinkan untuk digantikan 
posisinya. Sementara di sisi lain, ada beberapa objek yang menggunakan manusia demi mendukung skenario foto dari konsep yang sudah dibuat. Tanpa adanya manusia tersebut, foto menjadi kurang kuat dalam menyampaikan pesan yang tersimpan.

Untuk teknik pemotretannya menggunakan format warna sRGB Normal dengan sentuhan digital imaginguntuk merapikan serta koreksi warna pada hasil foto serta penambahan atau pengurangan beberapa elemen yang dianggap perlu pada foto tanpa adanya penambahan teks didalam badan foto.Dimana foto kebanyakan menggunakan background polos berwarna putihyang mengharuskan menggunakan pencahayaan yang tepat sehingga benda tetap terlihat detil nya dan tidak over atau under exposure.

Perapihan editing foto yaitu menghaluskan background foto yang mengkerut karena menggunakan kain serta merapihkan hasil guntingan gambar yang tidak dapat dilakukan dengan tangan ketika proses menggunting gambar tersebut. Sementara penambahan elemen foto dilakukan untuk melengkapi gambar yang tidak dapat ditangkap oleh kamera. Seperti foto asap yang terlalu tipis sehingga harus ditebalkan dan ditambahkan elemen asapnya. Sedangkan pengurangan elemen dilakukan untuk mengatasi beberapa objek yang tidak sengaja masuk kedalam frame foto ataupun noda yang terdapat pada objek atau kain background yang tidak bisa dibersihkan saat pemotretan berlangsung. Koreksi warna sekedar pengoreksian warna agar saat foto dicetak tidak melenceng jauh dari hasil digital-nya

Pada saat pemotretan, mode kamera yang digunakan adalah Manual, dengan mode fokus auto focus pada lensa, namun tetap menggunakan manual focus point, dimana penulis sendiri yang mengatur dimana jatuh titik fokus sesuai dengan konsep foto yan dikehendaki. Sedangkan pencahayaan menggunakan dua lampu continuous, dan dua buah lampu flash slave strobe berkekuatan 120 watt pada masing-masing lampu dan satu flash light berupa speedlite Yongnuo 460 MkI yang digunakan sebagai master flash untuk mentrigger kedua flash slave strobe yang menggunakan karakter white diffuser umbrella 40inch, dan tanpa karakter sama sekali, disesuaikan dengan konsep foto yang akan difoto.Produk ditaruh dalam mini light tent ukuran 110x110x110cm dengan background yang disesuaikan dengan warna objek (gelap/terang).

Beberapa foto pada konsep ini masih melibatkan manusia pada beberapa bagian anggota tubuhnya.Seperti yang banyak diambil pada pemotretan ini adalah tangan.Pada pemotretan manusia, penulis menggunakan mini studio dengan background kain putih ukuran 2x3 meter menggunakan background stand sebagai tempat meletakan kain background. Juga 
beberapa kali menggunakan karton putih untuk membuat foto efek tangan menembus pada karya "Stop Narkotika Now!"

Karena kekurangan model dimana penulis melakukan semua kegiatan proses memotret ini sendiri, penulis terkadang merangkap sebgai fotografer dan model untuk beberapa foto tangan dan anggota tubuh lain yang masuk kedalam frame yang ada di dalam foto. Meskipun ada pula dua foto terakhir (dari proses pemotretan, bukan nomor urut foto) menggunakan model orang lain karena memang sangat dibutuhkan citra yang berbeda dalam foto tersebut yang tidak dapat dilakukan oleh penulis. Kedua foto tersebut adalah "Marry Me" dan "Stop Narkotika Now!".

Pemotretan tetap menggunakan mode warna sRGB pada kamera, yang kemudian di edit dalam software edit foto, Photoshop CS 5.1 dibantu dengan Plug-In Nik Software 4 untuk mendapatkan efek foto yang sesuai. Efek yang digunakan adalah "bright contras" untuk menaikan High Keypada foto sehingga background putih bersih namun objek foto tetap mendapatkan detil dan exposure yang normal. Format foto yang selesai di-edit disimpan dalam bentuk JPEG Large (size Maximum - skala 12) dan TIFF (save with layers).

Penyimpanan foto dalam dua format bertujuan untuk mendapatkan hasil foto yang optimal serta efisien. Hal ini menjadi pertimbangan karena format JPEG lebih ringan ukurannya dan kompatibel untuk di tampilkan di berbagai macam media player, cetak kecil untuk masuk kedalam Laporan Karya Tugas Akhir, hingga media sosial jika ingin di unggah ke internet.

Sedangkan format TIFF yang menyimpan lebih banyak ukuran data file lebih bagus untuk pencetakan foto. Karena dengan ukuran file yang besar, data digital yang tersimpan lebih banyak dan luas, sehingga dapat diperbesar (extract) lebih bebas dalam ukuran yang lebih besar pula.

Sangat cocok untuk standarisasi cetak foto karya pameran yang mengharuskan cetak ukuran besar minimal 30x30 cm dengan kualitas ketajaman dan kedalaman warna yang tetap terjaga. 
Skema Proses Perwujudan Karya Fotografi Kreatif

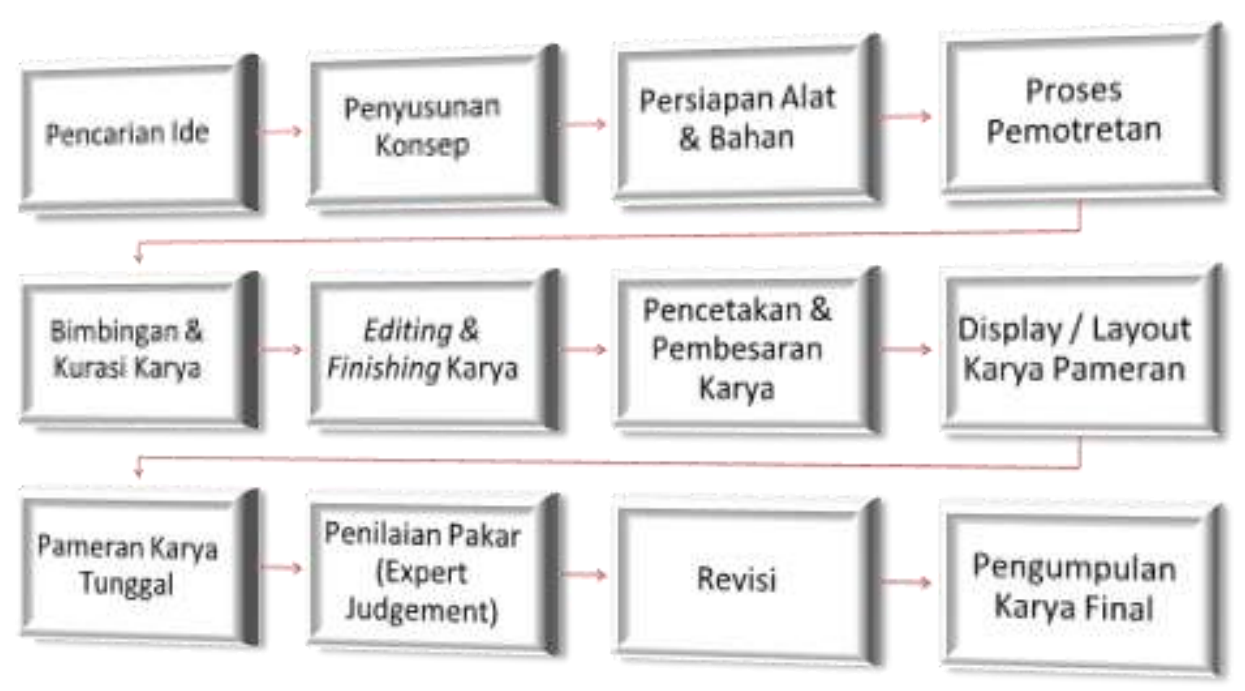

Pada bagian Hasil

Pembahasan ini penulis

menampilkan kedua puluh foto hasil

karya penulis yang ditambahkan dengan Lighting sketch untuk pedoman bagaimana setting lampu yang digunakan untuk mendapatkan hasil yang seperti penulis hasilkan.Penggunaan Lighting sketch ini mengambil dari karya Kevin Kertz yang dapat di unduh secara gratis dari website nya www.kevinkertz.com. File Lighting sketchhasil unduhan tersebut masih dalam bentuk format PSD (Photoshop File) sehingga masih dapat di rubah sesuai dengan setting pencahayaan yang penulis inginkan.Di dalam file tersebut, Kevin telah memberikan template gambar-gambar berbagai macam karakter lampu, background dan

objek yang dapat dipilih sesuai dengan foto yang penulis hasilkan.

Beberapa karakter yang dapat diaplikasikan kedalam Lighting sketchkarya Kevin Kertz yang sesuai dengan karya foto penulis diantaranya adalah diffuser board, umbrella diffuser white, non character strobe,object/model with shadow dan object/model whitout shadow. Karakter yang tidak ada pada Lighting sketch namun penulis gunakan pada pemotretan adalah continuous lamp dan speedlite flash.Penulis menggunakan non character strobe sebagai pengganti ikon gambar continuous lamp dan speedlite flash. Penulis juga menambahkan keterangan pada foto yang menggunakan ikon pengganti karena ketiadaan ikon. 


\section{Karya Foto 1 - Serangan Jantung}

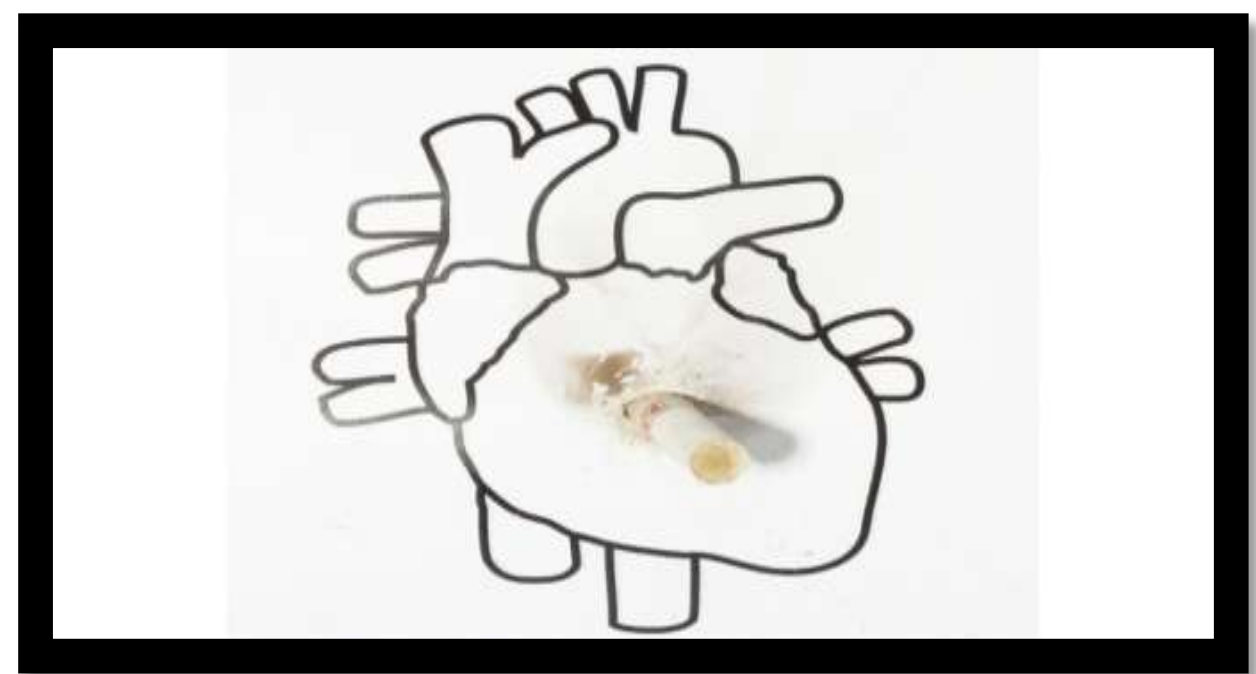

Gambar 3.1 Sketsa Rokok - Serangan Jantung

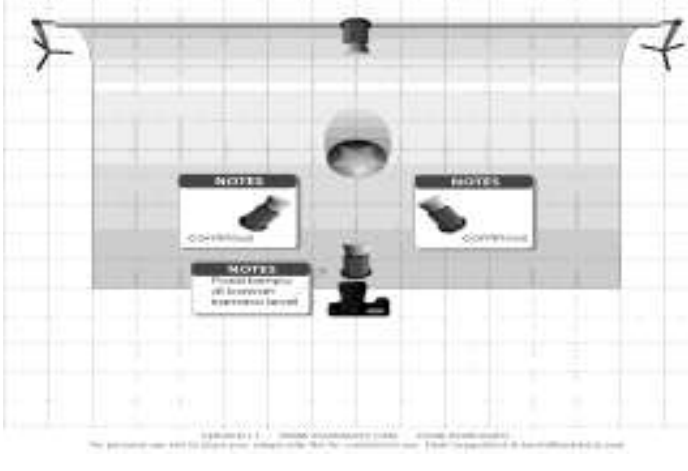

Pemotretan menggunakan dua buah lampu continuous yang merupakan lampu belajar dua buah disisi kanan dan kiri yang bertujuan untuk memberikan pencahayaan ke objek foto. Sementara penggunaan dua flash strobe dua buah disisi depan dan belakang. Strobe di belakang diarahkan ke background diperuntukan membuat High Keysementara strobe depan digunakan untuk fill inke objek. Strobe di belakang di posisikan 45 derajat dari background, sementara
Glossy Photo Paper 30x30cm Laminasi Glossy

Canon 550D with EF $100 \mathrm{~mm}$ Macro | 1/200 | f/11 | ISO 100 with 2 Flash

strobe depan diletakan sekitar $20 \mathrm{~cm}$ dibawah objek dengan jarak sekitar $30 \mathrm{~cm}$ dari depan objek.Kedua strobe tidak menggunakan karakter apapun, sehingga cahaya langsung mengenai objek foto.Sementara lampu contious menggunakan standard reflector bawaan tempat lampu.

Serangan jantung adalah salah satu akibat dari mengkonsumsi rokok secara berkepanjangan yang dapat menyebabkan kematian spontan tak terprediksi. 


\section{Karya Foto 2 - Kanker}

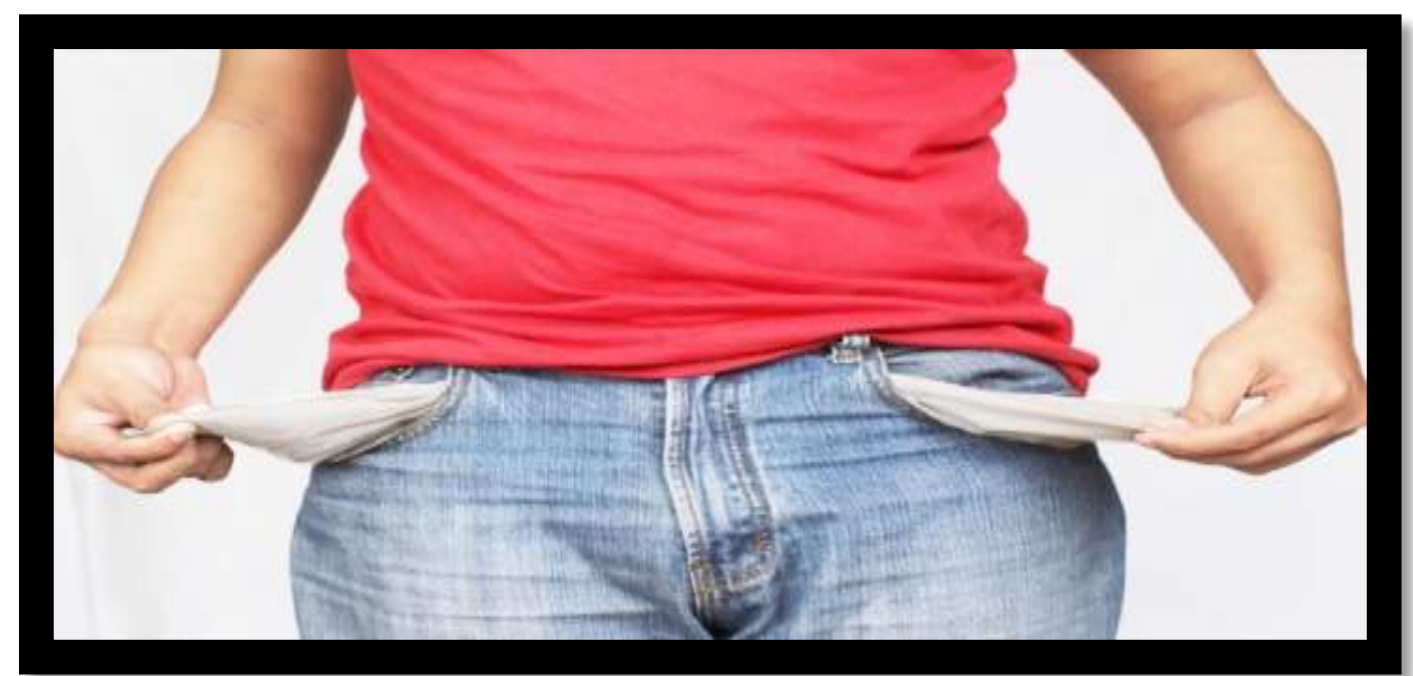

Gambar 3.2 Sketsa Rokok - Kanker

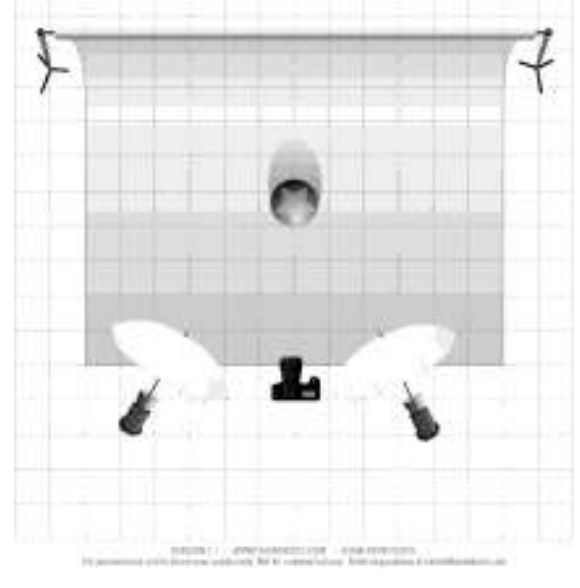

Pemotretan menggunakan dua buah lampu flash strobe menggunakan karakter umbrella diffuse white ukuran 40 inch sehingga penyebaran cahaya lebih luas dan merata. Sehingga membuat model mendapatkan fill in yang cukup dan tetap dapat membuat background High Key.Penggunaan strobe diatur 45 derajat kanan dan kiri model. Kanker identik dengan tumor atau adanya sel abnormal pada bagian tubuh yang menyebabkan disfungsi organ.Namun juga Kanker dapat diartikan "Kantong Kering"
Glossy Photo Paper 30x40cm Laminasi Glossy

Canon 550D with EF-S 18-55mm | $1 / 100$ | f/13 | ISO 100 with 2 Flash

sebuah guyonan yang mengindikasikan bahwa keadaan tidak memiliki uang atau dikenal dengan bokek. Masalah kesehatan ini tentu saja dapat berdampak secara langsung maupun tidak langusng terhadap perekonomian masyarakat yang ujung-ujungnya akan menyebabkan "Kantong Kering" jika penyakit yang diidap sudah dalam taraf membahayakan namun belum kunjung sembuh yang pada akhirnya biasanya hanya berbuah sia-sia karena sang penderita akhirnya meninggal dunia. 


\section{Karya Foto 3 - Dead}

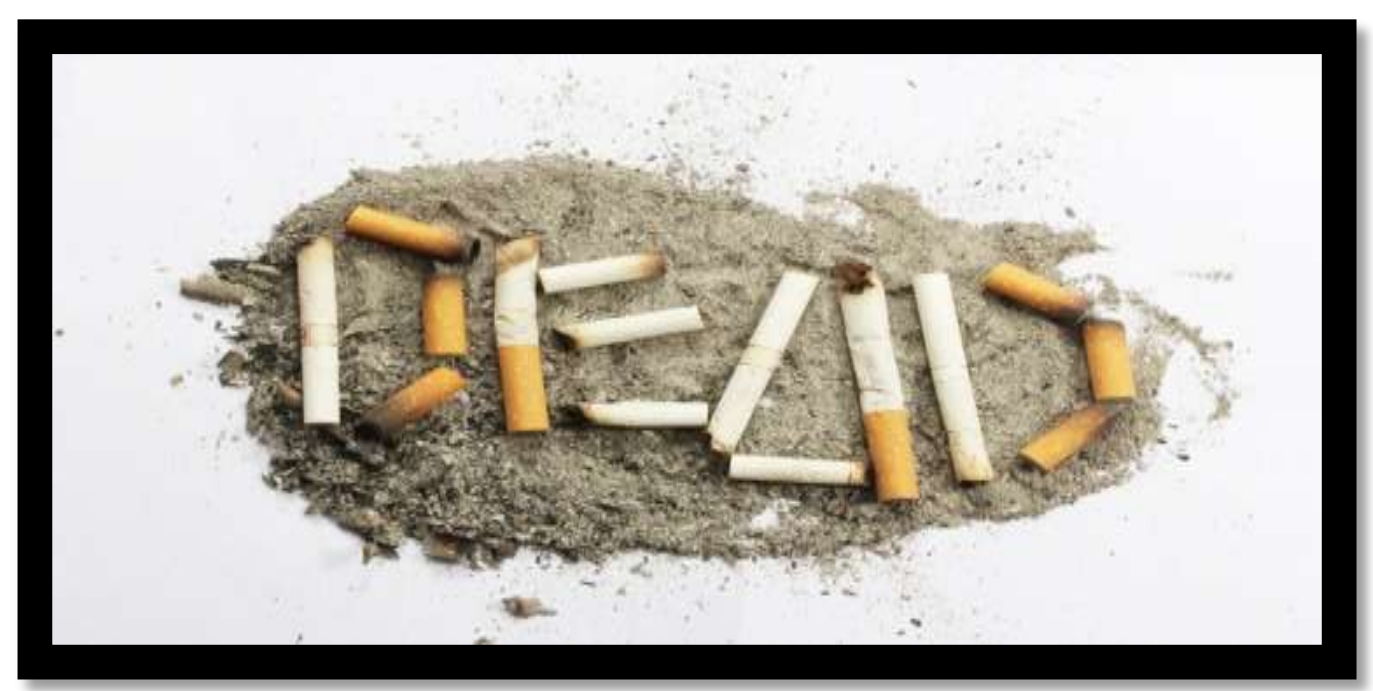

Gambar 3.3 Sketsa Rokok - Dead

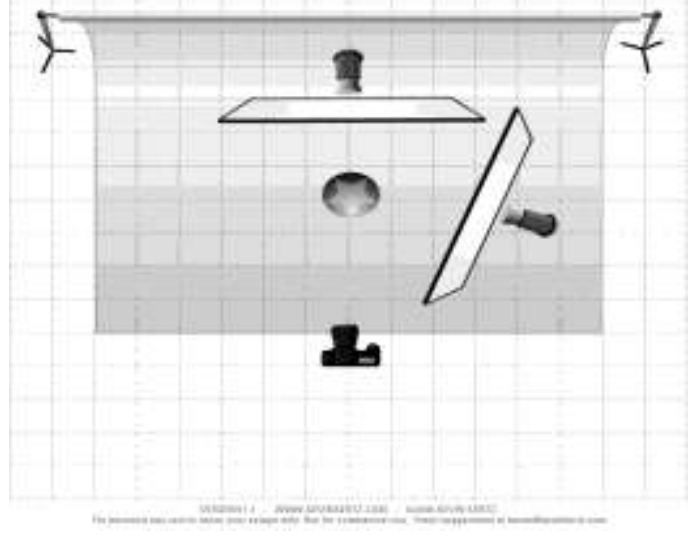

Pemotretan menggunakan dua buah lampu flash strobe yang diletakan di kanan objek serta belakang objek dengan ketinggian dan sudut yang berbeda. Pada strobe belakang, ketinggian diatur sekitar 60 centimeter dari objek dengan sudut kemiringan lampu 30 derajat dari background.Sementara pada strobe kanan ketinggan diatur sekitar 30 centimeter. Strobe tidak menggunakan karakter, namum di
Glossy Photo Paper 30x40cm Laminasi Glossy

Canon 550D with EF 100mm Macro | $1 / 160 \mid$ f/10 | ISO 100 with 2 Flash

atas objek diberi kertas kalkir sebagai diffuser agar cahaya yang dihasilkan flashstrobe merata.

Banyak perkataan bijak yang mengatakan "Matikan rokok Anda sebelum rokok mematikan Anda" namun pada kenyataannya banyak masyarakat yang baru mematikan rokoknya ketika mereka sudah dekat dengan kematian atau bahkan sudah meninggal dunia. 


\section{Karya Foto 4 - Killing You Slowly}

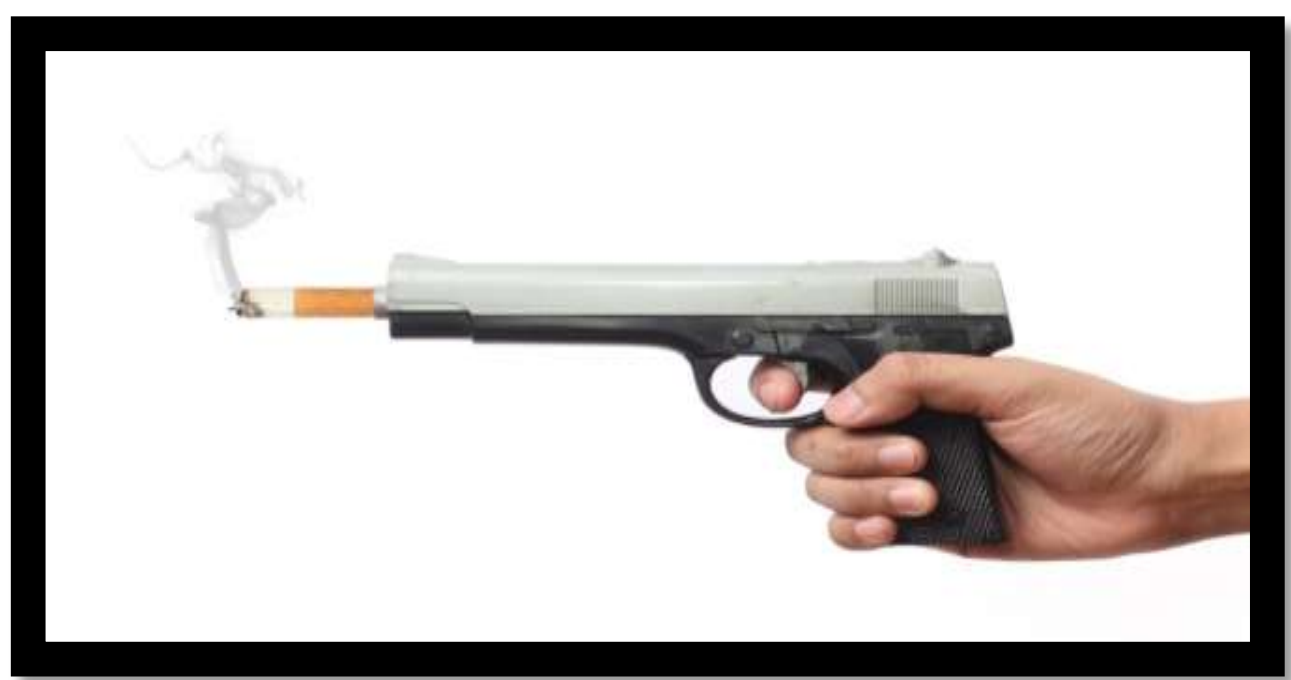

Gambar 3.4 - Sketsa Rokok - Killing You Slowly

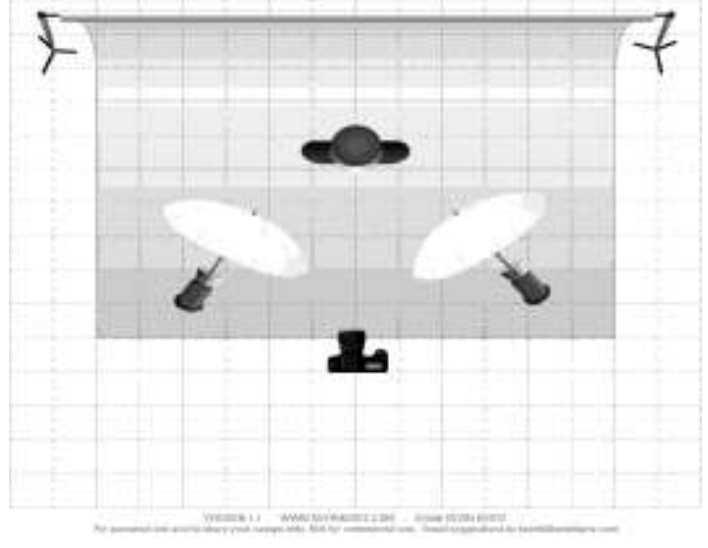

Pemotretan menggunakan dua buah lampu flash strobe menggunakan karakter umbrella diffuse white ukuran 40 inch sehingga penyebaran cahaya lebih luas dan merata. Sehingga membuat model mendapatkan fill in yang cukup dan tetap dapat membuat background High Key.Penggunaan strobe diatur 45 derajat kanan dan kiri tegak lurus langsung mengarah ke tangan model dan pistol yang digenggam.
Glossy Photo Paper 30x40cm Laminasi Glossy

Canon 550D with EF-S 18-55mm | $1 / 160 \mid$ f/10 | ISO 100 with 2 Flash

Masih mengutip dari perkataan bijak lainnya, "Merokok sama dengan bunuh diri" namun banyak masyarakat tidak menyadari itu.Karena pada dasarnya rokok mematikan perlahan-lahan, tidak seperti cepatnya peluru yang keluar dimuntahkan dari pistol yang memiliki waktu melesat keluar dari selongsongnya kurang dari satu detik. 


\section{Karya Foto 5-Simple Work Out}

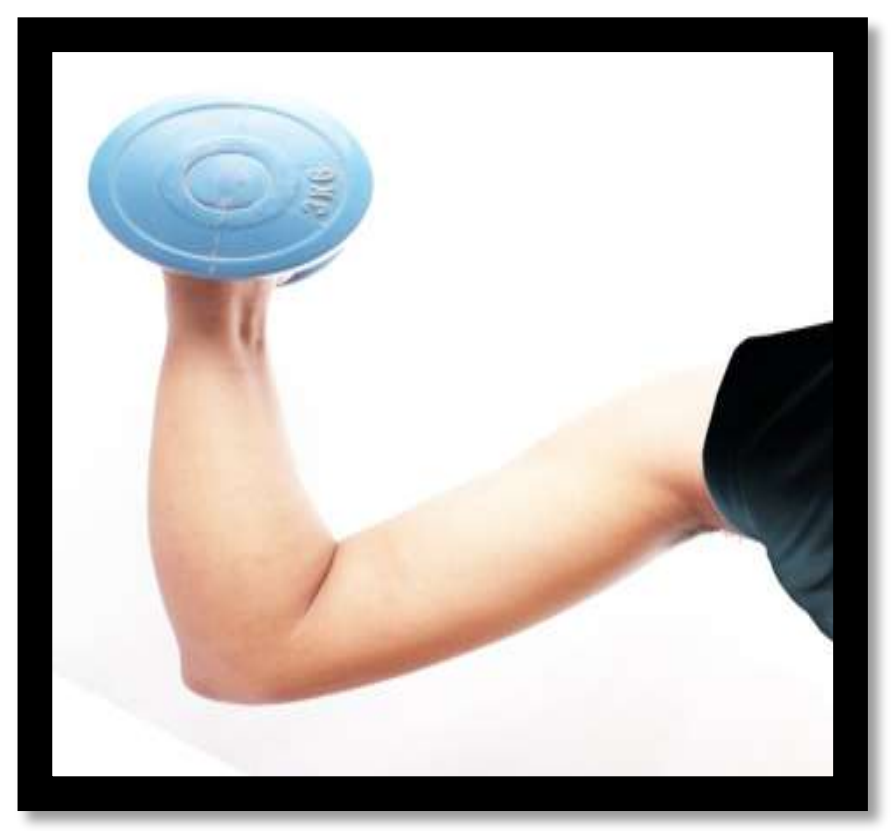

Gambar 3.5 - Sketsa Obesitas - Simple Work Out

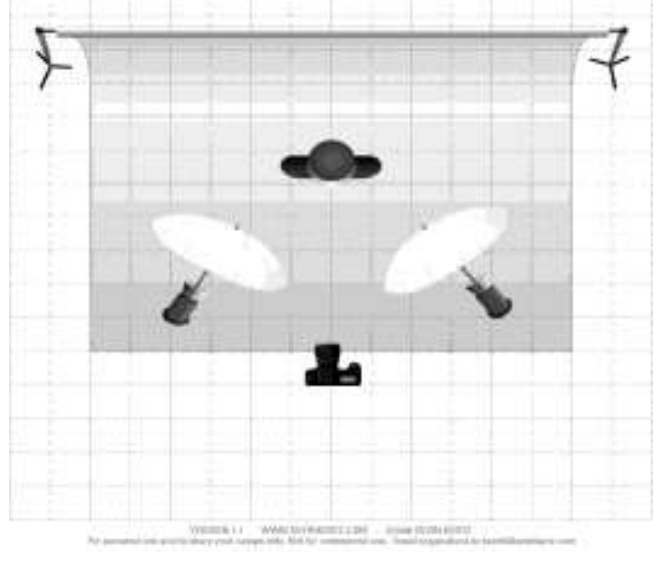

Pemotretan menggunakan dua buah lampu flash strobe menggunakan karakter umbrella diffuse white ukuran 40 inch sehingga penyebaran cahaya lebih luas dan merata. Sehingga membuat model mendapatkan fill in yang cukup dan tetap dapat membuat background High Key.Penggunaan strobe diatur 45 derajat kanan dan kiri tegak lurus langsung mengarah ke model.
Glossy Photo Paper 30x40cm Laminasi Glossy

Canon 550D with EF-S 18-55mm | 1/100 | f/11 | ISO 100 with 2 Flash

Obesitas bisa dicegah dengan banyak olahraga dan hidup teratur. Olahraga ringan sudah sangat cukup untuk membantu dalam menjaga kebugaran tubuh, stamina dan mencegah obesitas bagi orang-orang yang selalu bilang "sibuk" dan malas atau tidak sempat untuk melakukan olahraga berat seperti yang biasa dilakukan di tempat-tempat kebugaran 


\section{PENUTUP}

Beberapa hal yang dapat disimpulkan dari proses pembuatan karya ini adalah:

1. Foto iklan dengan teknik High Key tidak hanya membuat gambar lebih cerah, namun juga membuat gambar terkesan bersih.

2. Pemotretanstill life dan produk dapat dilakukan dengan menggunakan peralatan yang praktis, mudah dan dapat memanfaatkan berbagai macam alat dan bahan yang ada di sekitar kita.

3. Pemahaman semiotika sebagai ilmu tanda yang memiliki disiplin penjabaran akan kebenaran dan kebohongan dipakai sebagai penjabaran makna pesan yang terkandung di dalam foto karya.

4. Pencetakan foto menggunakan kertas glossy photo paper yang kemudian di laminasi glossy dapat meningkatkan brightness pada hasil cetak foto dengan kosekuensi kehilangan sedikit detil dari foto yang dicetak.

5. Penggunaan format file TIFF pada proses edit dan pembesaran foto sangat membantu dalam kualitas hasil cetakan foto, di mana pada format TIFF memoriakan data gambar tersimpan lebih banyak dan akurat.

\section{DAFTAR RUJUKAN}

Ambarsari, Riana. 2012. Buku Pintar

Fotografi: Food Photography.

Jakarta: PT. Elex Media

Komputindo.

Kusuma, Yuliandi. 2010. Strobist:

Trik Lighting Kreatif. Jakarta:

PT. Gramedia Widiasarana

Indonesia. 2011. Foto

Produk Murah dan Wah!

Jakarta: PT.

GramediaWidiasarana

Indonesia. 2011. OlahFoto

Digital untuk Fotografer.

Jakarta: PT.

GramediaWidiasarana

Indonesia.

Paulus, Edison \& Lealy Indah

Lestari. 2012. Buku Saku

Fotografi Still Life. Jakarta:

PT. Elex Media Komputindo.

Seto Wahyu Wibowo, Indiwan.

2013. Semiotika Komunikasi.

Jakarta: Penerbit Mitra Wacana

Media.

Surya Indra, Denny. 2012. Food

Photography Tutorial. Jakarta:

PT. Elex Media Komputindo. 